\title{
Organization of attack and other behaviors of White King pigeons exposed to intermittent water presentations
}

\author{
F. R. CAMPAGNONI, P. S. COHEN, and B. C. YOBURN \\ Northeastern University, Boston, Massachusetts 02115
}

\begin{abstract}
Six water-deprived pigeons were exposed to a fixed-time 90-sec water schedule with and without a conspecific target available. Target contacts and the pigeon's location in the test chamber during the interreinforcement interval were recorded, and the results were compared with those previously obtained with food reinforcement. Prior to target introduction, water-reinforced birds spent more total time in the front near the reinforcer dispenser and less in the rear than food-reinforced birds and, unlike food-reinforced birds, exhibited postreinforcement drinkinglike behaviors near the reinforcer dispenser before moving away from that area. With the target available, the level, topography, and duration of target-directed biting pecks were comparable for food- and water-reinforced pigeons. In contrast, the temporal organization of target pecks reflected the different temporal and spatial organizations of behavior prior to target introduction. For both food- and water-reinforced birds, the time between reinforcers at which a bird was spatially situated halfway between the front and rear of the chamber prior to target presentation was positively correlated with the time at which maximum target contact subsequently occurred.
\end{abstract}

Schedule-induced aggression is thought to be engendered by the general aversive (Azrin, Hutchinson, \& Hake, 1966; Falk, 1977) and arousing (Killeen, 1979) properties of intermittently scheduled positive reinforcement and, consequently, not considered a unique property of a particular reinforcer. This general process view is consistent with demonstrations of schedule-induced attack in rats and monkeys, using various reinforcers, including food (e.g., Deweese, 1977; Gallup, 1965), morphine (e.g., Boshka, Weisman, and Thor, 1966), and electrical brain stimulation (Huston and DeSisto, 1971; Hutchinson and Renfrew, 1978), and with the results of studies with humans, using money and smoking as reinforcers (Frederiksen \& Petersen, 1977; Hutchinson \& Emley, 1973). The assortment of reinforcers used in these studies contrast sharply, however, with the exclusive use of food reinforcement in the more extensive and systematic experiments with pigeons (e.g., Azrin, Hutchinson, \& Hake, 1966), which have provided the primary data base for evaluating current theory.

The need to explore schedule-induced attack in pigeons with reinforcers other than food has recently

This research was supported in part by USPHS Grants RR07143 and R03MH34332-01 to Northeastern University and partially fulfilled the requirements for the MA degree for the first author. We thank Jim Palmer, Jerry Schrader, and Liz Callender for technical assistance and Philip Zeigler for comments on an earlier version of the manuscript. Portions of these data were presented at the 1980 Annual Meeting of the Eastern Psychological Association, Hartford, Connecticut. Reprints may be obtained from F. R. Campagnoni, Department of Psychology, Northeastern University, Boston, Massachusetts 02115. been underscored by evidence (Reberg, Innis, Mann, \& Eizenga, 1978) that intermittently scheduled food and water reinforcement differentially affect the organization of nonaggressive behavior in pigeons. Specifically, pigeons spend more time in the vicinity of the dispenser and exhibit fewer behavior patterns when given intermittent access to water than when given comparable access to mixed grain. Furthermore, water-reinforced birds engage in drinking-like behaviors around the water dispenser after water withdrawal, whereas when receiving food, they tend to walk away from the dispenser.

In view of the narrower range of nonaggressive behavior that occurs with water reinforcement and the possibility that postwater, hopper-directed activities might disrupt or block schedule-induced attack, Experiment 1 examines the temporal and spatial organization of behavior in pigeons receiving intermittent water both with and without a target available. The results are compared with those of a previous experiment with pigeons (Yoburn, Cohen, \& Campagnoni, 1981) which used food under otherwise identical conditions.

\section{EXPERIMENT 1}

\begin{abstract}
Method
Subjects. The subjects were six experimentally naive male White King pigeons water-deprived to $75 \%( \pm 20 \mathrm{~g})$ of their ad-lib weights. The birds were housed in individual cages under a light-dark cycle (lights on 0700-2300 h) and had free access to mixed grain and health grit. Supplementary water was provided following test ses-
\end{abstract}




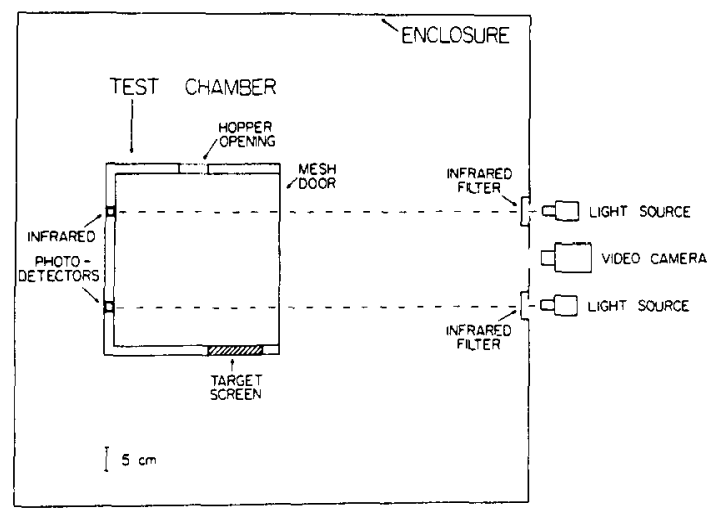

Figure 1. Schematic diagram of the experimental chamber. (From Byron C. Yoburn, Perrin S. Cohen, and Frank $R$. Campagnoni. The role of intermittent food in the induction of attack in pigeons. Journal of the Experimental Analysis of Behavior, 1981, 35, 101-117.)

sions, as required to maintain stable body weight. Wing and tail feathers were clipped periodically.

Apparatus. The test chamber was identical to that used to investigate attack in food-reinforced pigeons (Yoburn et al., 1981), with the exception that the food hopper (BRS/LVE GEM-001) was modified by removing the grain magazine and replacing it with a .5-cc dipper that was submerged between water presentations in a water reservoir that was inaccessible to the subject. The external and internal dimensions of the hopper and hopper light were the same as those of the food dispenser. Figure 1 is a schematic diagram of the chamber. The dispenser was located on one wall (front), and a photographic target of a conspecific, mounted on microswitches (Looney \& Cohen, 1974), could be made available on the opposite wall (rear) of the chamber. Two infrared light beams passed through the grid door and onto photoreceptors on the opposite wall, allowing the pigeon's location during the interreinforcement interval to be recorded to the nearest $.01 \mathrm{~min}$ in the front, middle, or rear of the chamber. Attack responses and the subject's location were recorded as a function of time since water delivery in successive 15 -sec intervals (six time bins). Standard electromechanical programming apparatus located in an adjacent room controlled and recorded experimental events.

Procedure. With the conspecific target unavailable, each bird was trained to drink from the water dipper. Beginning with the session after hopper training, pigeons were exposed to a fixedtime (FT) 90-sec water schedule, which consisted of presenting a .5 -cc dipper of water for $7 \mathrm{sec}$ at 90 -sec intervals. Water-reinforcers were scheduled independently of the subject's behavior. Each session consisted of 16 reinforcer deliveries and began and ended with a water delivery. As indicated in Table 1 , the birds initially were exposed to the water schedule without the target available (Sessions 1-15) followed by 15 sessions (Sessions 16-30) with the target present. The target was then covered with a piece of black paper for Sessions 31-40, followed by 15 sessions (Sessions 41-55) in

Table 1

Sequence of Experimental Conditions in Experiment 1

\begin{tabular}{ccl}
\hline Phase & Sessions & \\
\hline 1 & $1-15$ & No Target/Water \\
2 & $16-30$ & Target/Water \\
3 & $31-40$ & No Target/Water \\
4 & $41-55$ & Target/Water \\
5 & $56-70$ & Target/Sham Water \\
6 & $71-85$ & Target/Water \\
\hline
\end{tabular}

which the image was again present. During Sessions 56-70, a sham water schedule was in effect. With the target present, the hopper light and dipper operated normally on the fixed-time schedule but no water was presented. The sham water schedule was followed by 15 sessions (Sessions 71-85) in which water was again presented on the fixed-time schedule with the target present. A video camera allowed monitoring of behavior during the experimental sessions, and recordings were made of selected sessions.

\section{Results and Discussion}

Behavior prior to target introduction. During the 15 sessions prior to target introduction, the pigeons spent a mean of $80 \%$ of their total time in the front of the chamber, $9 \%$ in the middle, and $11 \%$ in the rear. Each animal developed a characteristic pattern of movement within the test chamber between water deliveries, although there were some general similarities among birds. To facilitate comparison among subjects, Figure 2 plots relative time in each location as a function of time since water delivery for the 15 sessions prior to target introduction. Four of the six birds allocated relatively more time to the front of the chamber during the first half of the interwater interval than they did during the second half. For all birds except P8551, the relative amount of time spent in the rear increased as the interval progressed. Time in the middle was more variable across subjects, but for four of six birds, the maximum occurred most often 15-75 seconds into the interval.

These results differ from those previously reported for pigeons receiving fixed-time food deliveries under identical conditions (Yoburn, 1979; Yoburn et al., 1981) in terms of the total amount of time spent in each spatial location, the temporal organization of movement in the test chamber between reinforcers, and the topography of behavior during the postreinforcement period. Figure 3 shows that both waterand food-reinforced birds spent the majority of total session time in the front during the last five sessions prior to target introduction. Pigeons receiving water, however, spent significantly more time in the front and significantly less in the rear than the birds that received food (in both cases, two-tailed Mann-Whitney $U=5, p<.05$ ). Time spent in the middle was not significantly different for the two groups.

Figure 4 plots, for food-reinforced birds in the Yoburn (1979) study, relative time spent in each location as a function of time since food delivery for the 15 sessions prior to target introduction. A comparison of these data with those in Figure 2 shows that birds on the intermittent water schedule also differed from those given food in terms of how they allocated time to each of the three spatial locations within the interval between food deliveries. Food-reinforced birds consistently spent the most time in the middle of the chamber during the $15 \mathrm{sec}$ following reinforcement termination, whereas, for water-reinforced birds, 
P8773

P8738

P9192

P9233

P9478

P8551


TIME SINCE WATER (SECONDS)

Figure 2. Relative time spent in each location (front, middle, rear) as a function of time since a water delivery for each subject in Experiment 1 prior to target introduction. Relative time was calculated by dividing time allocated to successive 15 -sec intervals following water delivery by total time in each location. The number in parentheses corresponds to the proportion of total session time spent in each location for each bird.

maximum time in the middle varied across subjects, ranging from the first $15 \mathrm{sec}$ following reinforcement to $15 \mathrm{sec}$ prior to reinforcement delivery. Unlike water-reinforced birds, which tended to remain in the front near the dispenser immediately after water delivery and subsequently to spend less time in that area (and more time in the rear) as the interval progressed, food-reinforced birds (except P9242) did just the opposite. This latter difference, however, must be viewed with some caution. Videotaped records suggest that the generic nature of time allocation as a behavioral measure may have obscured important similarities in the way that food and water influence the temporal organization of behavior near the dispenser. During the time that the water-reinforced birds were in the front during the postreinforcement period, they engaged in hopper-directed activities (drinking motions with head in magazine, pecks at magazine). These activities differed from pacing-in-the-front that occurred prior to water delivery. Food-reinforced birds, on the other hand, spent virtually no time engaging in hopperdirected activities in the postreinforcement period but did exhibit pacing-in-the-front prior to reinforcement delivery. If pacing-in-the-front had been separately recorded for water-reinforced birds, the temporal distribution of that behavior within the interwater interval might have resembled the distribution of time in the front shown in Figure 4 for foodreinforced birds. Time allocation to a particular location may be, in some instances, a complex measure that must be supplemented by additional measures (cf. Baum \& Rachlin, 1969).

In sum, the temporal, spatial, and topographical organization of the behavior of pigeons exposed to a fixed-time 90 -sec water reinforcement schedule is different in several respects from that which occurs with an identical food reinforcement schedule. This is consistent with the results of Reberg et al.'s (1978) experiment and indicates that the differential behavioral effects of intermittent food and water rein- 


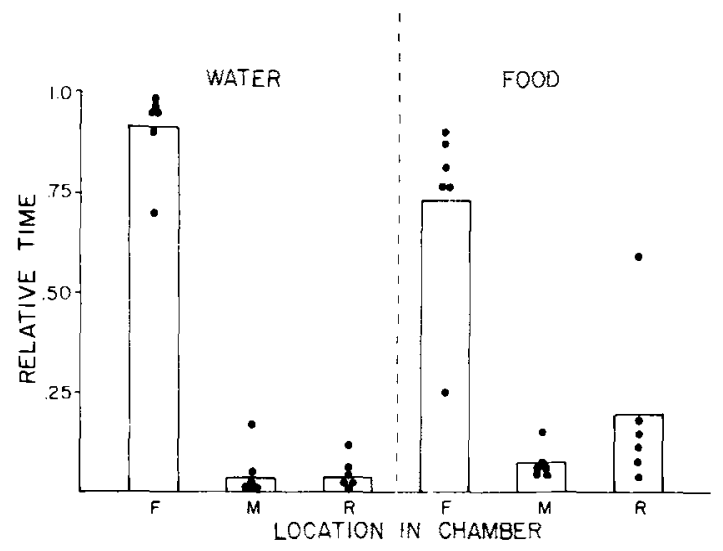

Figure 3. Histograms are the mean proportion of total session time allocated to each location (front, F; middle, $M$; rear, $R$ ) during the last five sessions prior to target introduction for food(Yoburn et al., 1981) and water-reinforced birds. Data points correspond to the results for individual birds.

forcement noted in that experiment were not, as those authors suggested, peculiar to the subject's reinforcement history, to idiosyncrasies of the testing apparatus, or to the relatively short $(15-30 \mathrm{sec})$ interreinforcement interval employed.
Behavior after target introduction. When the target was introduced, five of six birds engaged in sustained attack over the initial 15 sessions with the target available. For those birds, an attack occurred in $50 \%$ or more of the interreinforcement intervals, which is comparable to that reported for pigeons exposed to intermittent food schedules (e.g., Yoburn et al., 1981). When compared directly with data obtained with food under identical conditions (Yoburn et al., 1981), there was no statistically significant difference between food- and water-reinforced birds in terms of the number of subjects exhibiting sustained attack, rate of attack, or the number of intervals with an attack.

Although equally effective in inducing attack in pigeons, the temporal organization of attack in the interval between food (Yoburn et al., 1981) and water reinforcers was quite different. This is shown in Figure 5, which plots relative frequency of attack as a function of time since a reinforcer. For all birds on the water schedule, except P8551, relative frequency of attack increased over the initial $30 \mathrm{sec}$ of the interval and reached a maximum at various points late in the interval. For P8551, maximum rate of at-
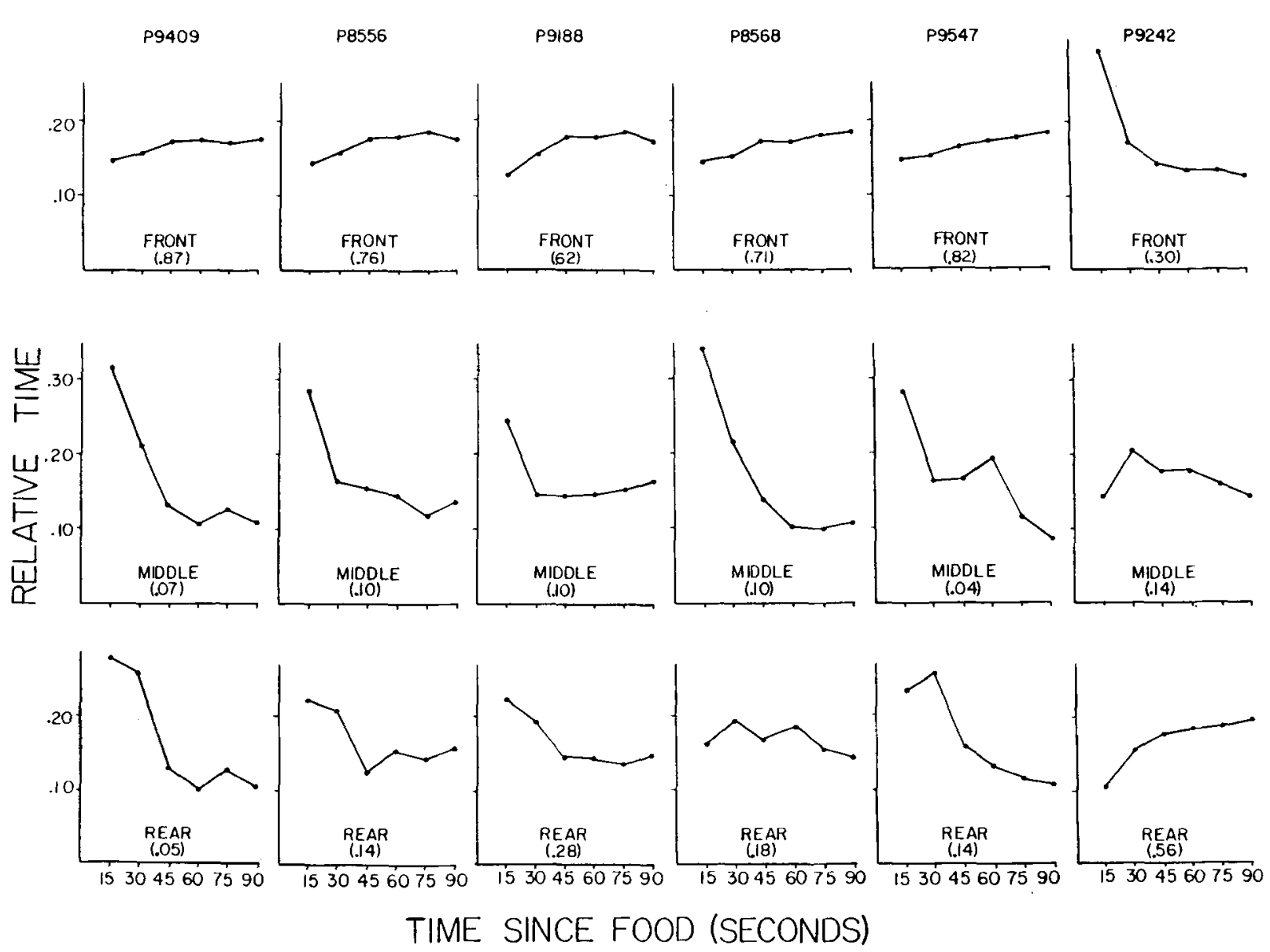

Figure 4. Relative time spent in each location (front, middle, rear) prior to target introduction, as a function of time since a food delivery for each subject, in an experiment by Yoburn (1979). See legend of Figure 2 for details. 


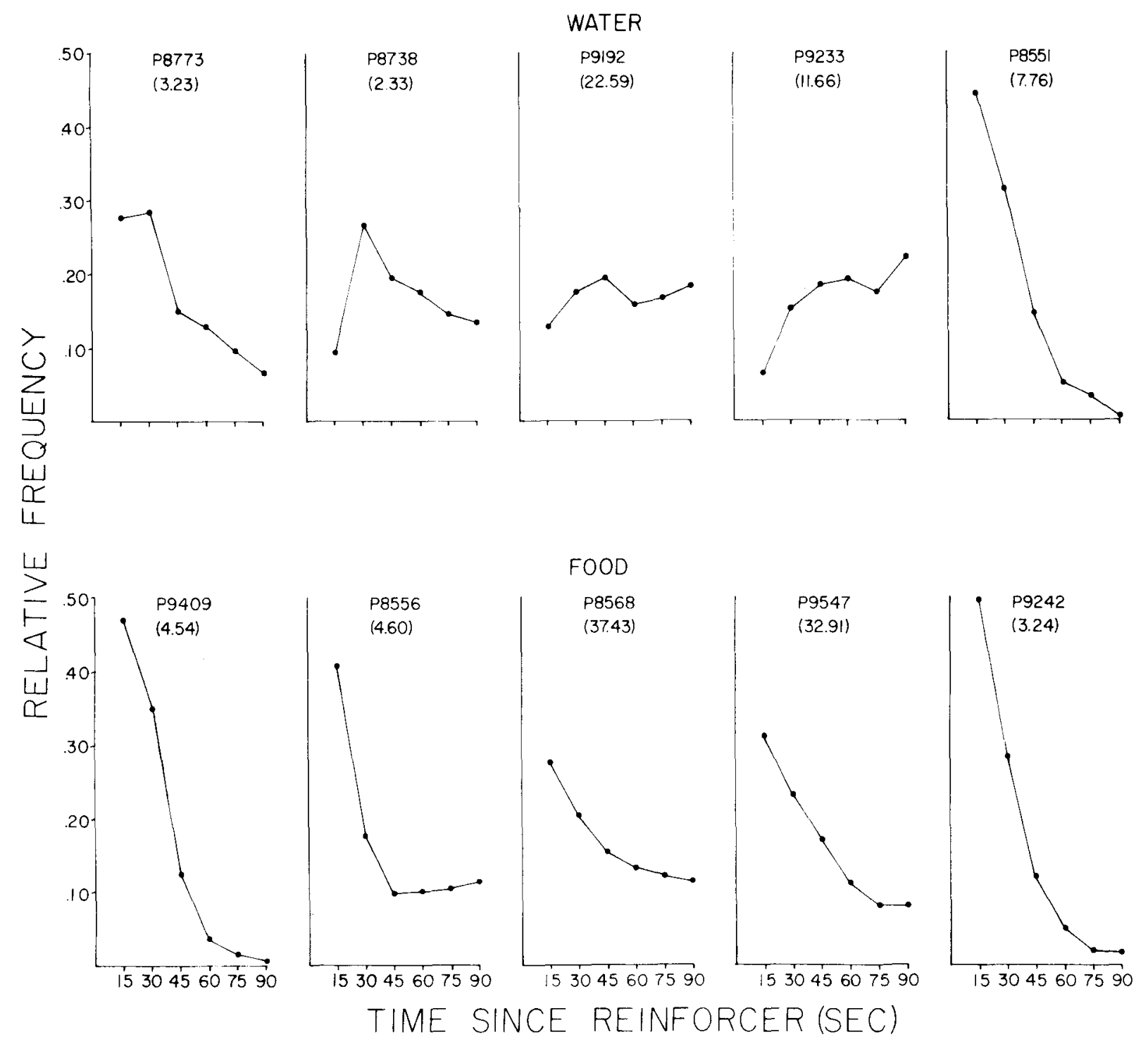

Figure 5. Relative frequency of attack (number of attacks in each bin divided by total number of attacks) as a function of time since a reinforcer for birds receiving water and food (data from Yoburn et al., 1981) reinforcement. The number in parentheses is the rate of target contacts over the initial 10 sessions with the target available.

tack occurred during the initial $15 \mathrm{sec}$ after water reinforcement, although, when the target was subsequently reintroduced in Phase 4, maximum attack rate occurred $15-30 \mathrm{sec}$ after reinforcement and remained at that point throughout further testing. These results contrast sharply with the immediate postreinforcement pattern of attack that typically develops during exposure to intermittent food reinforcement (e.g., Yoburn \& Cohen, 1979). As shown in the bottom panel of Figure 5 , under conditions identical to those of this study (Yoburn et al., 1981), maximum attack following food delivery consistently occurred during the first $15 \mathrm{sec}$ following reinforcement.

After target introduction, all water-reinforced birds showing sustained attack spent more time in the rear of the chamber (where the target was located) and less in the front and middle than they had prior to target presentation. Mean time in the front, middle, and rear prior to and following target introduction was $80 \%, 9 \%, 11 \%$ and $72 \%, 3 \%, 25 \%$, respectively. In contrast, the pigeon that did not exhibit sustained attack (P9478), spent more time in the front (away from the target) and less in the middle and rear after target introduction, suggesting that for that nonattacking bird, the target was not simply ineffective or neutral but rather aversive. Although sufficient data are not available in this experiment to further assess this possibility, the measurement of spatial location as used in this experiment has the po- 
tential advantage of assessing the behavior of nonattacking as well as attacking animals.

For subjects showing sustained attack, the temporal distribution of attack between successive reinforcers was positively correlated (Table 2) with the distribution of time spent in the rear following target introduction and negatively correlated (Table 2 ) with the distribution of time allocated to the front. Distribution of time spent in the middle was unrelated to the temporal pattern of attack.

The role of the target and water schedule in the maintenance of attack is indicated in Figure 6, which shows the mean number of interwater intervals with at least one target contact over successive sessions for all birds in Experiment 1. The results show that, as with previous studies with food reinforcement (e.g., Looney \& Cohen, 1974), schedule-induced attack in this study was controlled by the conspecific image and the intermittent water schedule was necessary to maintain attack. Covering the target (Phase 3, Sessions 31-40) resulted in an abrupt decrease in the rate of target contact to near zero levels for all birds that had exhibited sustained attack. Attack frequency returned to original levels when the image was reintroduced (Phase 4, Sessions 41-55). Removal of water reinforcement during the sham water sessions (Phase 5, Sessions 56-70) resulted in a gradual decrease in attack for all animals that had shown sustained attack. For all subjects, the temporal distributions of time in the front, middle, and rear of the chamber (not shown) gradually changed during the sham water sessions until they were nondifferential with respect to presentations of the dry dipper during the final five sessions. When water was again presented (Phase 6, Sessions 71-85), attack recovered to original levels and (except for P8551, discussed above) the temporal organization of attack and movement returned to the pattern displayed prior to exposure to the sham water condition.

A comparison of Figures 2 and 5 shows that, for water-reinforced birds, time spent in the middle of the chamber prior to target introduction was posi-

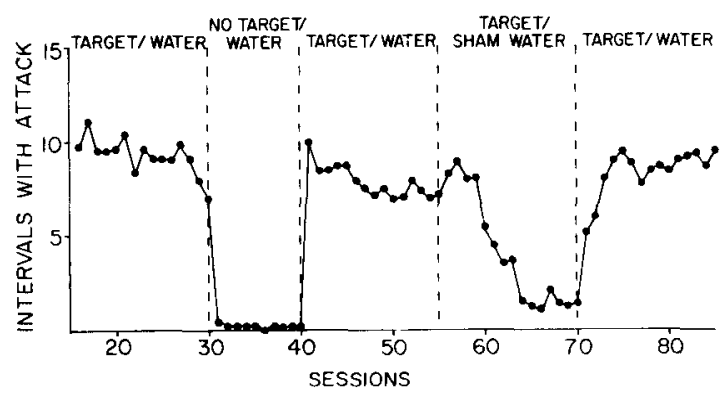

Figure 6. Mean number of interwater intervals of a possible 15 in which at least one target contact occurred for all six pigeons in Experiment 1. The dashed lines correspond to changes in target and schedule conditions over Sessions 16-85, as indicated in Table 1. tively correlated with subsequent attack distributions. For all five birds that exhibited sustained attack, the time following reinforcement at which a pigeon was most often in the middle of the chamber was the time at which the highest frequency of attack occurred when the target was presented. As indicated in Table 2, Pearson product-moment correlations between time in the middle and subsequent target contact were positive, whereas corresponding correlations between time in the front and target contact were negative. Four of the five positive correlations and three of the five negative ones were statistically significant. In contrast, the distribution of time in the rear prior to target introduction was not correlated with the subsequent distribution of target contacts. The time at which a pigeon was most often at the place where the target was to be introduced (rear) did not coincide with the time at which the highest frequency of attack subsequently occurred.

A comparison of Figures 4 and 5 shows that for food-reinforced birds (Yoburn, 1979) that exhibited sustained levels of attack, the distribution of total time in the middle prior to target introduction was positively correlated with the subsequent distribution of target contact, as it was for those given water. As was the case for water-reinforced pigeons, there was a statistically significant correlation between these two measures in four of five subjects (Table 2). Unlike the water-reinforced birds, however, both time in the front and time in the rear were correlated with the subsequent distribution of target contact. Time in the front was negatively correlated with target contact and time in the rear was positively correlated with target contact for all birds except for P9242, for which, for unknown reasons, the correlations were reversed. As shown in Table 2, 9 of 10 of these latter correlations were statistically significant.

In summary, the temporal distributions of time in the front of the chamber prior to target introduction were negatively correlated with the subsequent distributions of target contact. Time allocated to the rear, where the target was introduced, was a good predictor of the subsequent distribution of attack for some food-reinforced pigeons. Time spent in the middle was the best overall predictor of the subsequent distribution of attack for all birds. These latter correlations occurred even though, across birds, maximum attack rates were observed at five different temporal locations (one for the food birds and four for the water birds) within the interval between reinforcers and the target was presented in the rear (and not the middle) of the chamber. It is possible that the consistent correlation between time in the middle and attack resulted from birds launching attacks against the rear-mounted target from the middle of the cham ber. This, however, is inconsistent with high positive correlations that occurred for all 10 birds (Table 2), 
Table 2

\begin{tabular}{|c|c|c|c|c|c|c|}
\hline \multirow[b]{2}{*}{ Subject } & \multicolumn{3}{|c|}{ Spatial Location With Target Unavailable } & \multicolumn{3}{|c|}{ Spatial Location With Target Available } \\
\hline & Front & Middle & Rear & Front & Middle & Rear \\
\hline & & & Water & & & \\
\hline 8551 & $-.94 *$ & $+.99+$ & +.68 & $-.99 *$ & .00 & $+.99 \dagger$ \\
\hline 8773 & -.21 & $+.93+$ & -.76 & $-.88^{*}$ & +.13 & $+.94+$ \\
\hline 9192 & $-.84^{*}$ & $+.87 \dagger$ & +.56 & $-.88^{*}$ & +.02 & $+.98 \dagger$ \\
\hline 8738 & $\begin{array}{l}-.04 \\
-.49\end{array}$ & $+.91+$ & $\begin{array}{r}+.16 \\
+.16\end{array}$ & $-.92 *$ & .00 & $\begin{array}{r}+.89+ \\
+\end{array}$ \\
\hline \multirow[t]{2}{*}{9233} & $-.83^{*}$ & +.60 & +.80 & $-.98^{*}$ & +.07 & $+.98 \dagger$ \\
\hline & & & Food & & & \\
\hline 9242 & $+.96 t$ & -.03 & $-.99 *$ & $-.91^{*}$ & -.27 & $+.97 \dagger$ \\
\hline 8568 & $-.98^{*}$ & $+.99+$ & +.26 & $-.93^{*}$ & $-.92^{*}$ & $+.98 \dagger$ \\
\hline 9547 & $-.96^{*}$ & $+.83+$ & $+.92 \div$ & $-.99 *$ & +.99 & $+.99+$ \\
\hline 8556 & $-.97^{*}$ & $+.97+$ & $+.83 t$ & $-.89 *$ & $+.86+$ & $+.90+$ \\
\hline 9409 & $-.98^{*}$ & $+.96 \dagger$ & $+.98^{\dagger}$ & $-.99^{*}$ & $+.99 \dagger$ & $+.99+$ \\
\hline
\end{tabular}

Note-The left panel shows, for individual birds, correlation coefficients (Pearson product-moment correlations, df $=4$ ) between the distribution of time allocation in each spatial location for the 15 sessions prior to target introduction with the subsequent distribution of target contact during the 10 sessions after target introduction. The right panel shows, for the same birds, correlation coefficients (Pearson product-moment correlations, $d f=4$ ) between the distribution of time allocation in each spatial location for the 10 sessions after target introduction with the distribution of target contact for those same sessions. In both positive and negative correlations, statistical significance was determined by the results of two-tailed t tests $(\alpha=.05) . \quad{ }^{*}$ Statistically significant negative correlations. TStatistically significant positive correlations.

with the target available, between distributions of time in the rear and target contact and with the lack of such correlations between time in the middle and attack for 7 of the 10 birds.

In general, these correlational data are consistent with Falk's (1977) hypothesis that schedule-induced attack stems from conflict between opposing behavioral vectors to approach and escape (e.g., Brown \& Flory, 1972) from intermittently available reinforcers. According to this hypothesis, adjunctive attack, like displacement activities, should occur with maximum frequency when behavioral conflict is maximum (McFarland, 1969; Rowell, 1961). If one assumes that time allocation in the front of the chamber in this experiment reflects, in part, a reinforcementapproach vector, that location in the rear reflects a competing escape vector, and that location in the middle reflects response-competitive pauses and transits between competing activities, then the data are consistent with Falk's notion that conflict mediates attack. Of 10 pigeons displaying sustained attack ( 5 in each condition), 9 had the highest frequency of attack at the time when they spent the most time pausing in or passing through the center of the chamber prior to target introduction. Furthermore, differences in the temporal locus of time spent in the middle of the chamber, across subjects, was accompanied by a corresponding change in the temporal locus of attack. To further evaluate this hypothesis, additional research must explicitly manipulate and directly measure conflict between tendencies to approach and withdraw from intermittent reinforcement.

\section{EXPERIMENT 2}

Videotaped recordings taken in Experiment 1 showed that the gross topographical features of target contact following interrupted access to water reinforcement are comparable to those that occur following interruption of food reinforcement. In both cases, pigeons charged and pecked at the head of the conspecific target image. The next experiment was undertaken to determine if the precise form and time course of an agressive peck is different following interruption of food and water reinforcement.

\section{Method}

Subjects. The subjects were six male White King pigeons, three from Experiment 1 (P9192, P8551, P8738) and three pigeons from the Yoburn et al. (1981) study which had been exposed to the fixed-time food schedule (P8556, P8568, P9242). All birds were housed under the same conditions used in Experiment 1 , except that food-reinforced birds were deprived to $75 \%( \pm 20 \mathrm{~g})$ of adlib weight and had free access to health grit and water as in the original Yoburn et al. study.

Apparatus. The experimental chamber was identical to the one described in Experiment 1 except that it was not equipped with the photodetection system used in that study. The ceiling of the chamber was replaced with a clear piece of Plexiglass. Two $100-W$ incandescent bulbs with metal reflectors were situated directly above and in front of the Plexiglas chamber door. Movies were taken with a Palliard Bolex 16-mm camera, fl.8, 64 frames/second, double shutter, at a distance of $.5 \mathrm{~m}$.

Procedure. For photographic purposes, chamber illumination was higher in this experiment than in Experiment 1. Small-step in creases in illumination during successive sessions habituated the pigeons to the high-intensity light. Increases in chamber illumination often resulted in disruption of attack behavior (but not feeding or drinking), and up to 40 sessions were required to obtain reliable attack under conditions of full illumination. 
During a filming session, seven 10-sec attack sequences were recorded for each pigeon. The sequences were filmed during seven different interreinforcement intervals.

\section{Results and Discussion}

Frame-by-frame analysis of the movies showed that the time course and topography of an aggressive peck were comparable following food and water reinforcement. The initial target-directed peck following both water and food presentation was directed toward the head of the target and was between 150 and $200 \mathrm{msec}$ in duration, as measured from the beginning to end of eye closure.

This motor sequence is distinct from the pigeon's longer duration drinking response (Jenkins \& Moore, 1973), in which the eye remains open and the beak is partially closed. On the other hand, it is similar to the pigeon's food-directed peck (Zeigler, 1976, Figure 1), although there may be differences in terms of gape, force, and other aspects of the response. This biting aspect of schedule-induced attack is consistent with other observations (e.g., Rilling, 1977, Figure 20) that pigeons pull feathers from the head and neck region of live and stuffed targets. Biting thus appears to be a major component of aggression engendered by intermittent reinforcement in pigeons, as it is in monkeys (DeWeese, 1977), rats (Thompson \& Bloom, 1966), and possibly humans (Hutchinson et al., 1977).

The similarity of attack motor sequences following interruption of food and water reinforcement supports Falk's (1971) hypothesis that adjunctive behaviors reflect a class of activities that are distinct in origin from conditioned responses. Previous studies with pigeons have shown that the topography of both operant (Wolin, 1968) and Pavlovian (Jenkins \& Moore, 1973) conditioned pecks mirror the topographic form of ingestive behavior associated with the reinforcer used. This was not the case in this experiment, in which the topographic form and time course of the initial attack following both water and food reinforcement were similar to each other as well as the pigeon's feeding peck. This conclusion, however, must be qualified in one respect. In a few cases, one water-reinforced bird (P8551) displayed drinking-like pecks near the target following the initial biting response in an interval and before initiation of subsequent bites within that interval. The origin of these water-related pecks is unknown. They may reflect drinking of residual water dislodged by target contact or they may possibly correspond to nondirected water-type pecks that sometimes occurred in other areas of the test chamber and that may have originated through Pavlovian or operant conditioning processes.

Results obtained with food-reinforced subjects bear on another issue raised by Innis and Honig
(1979). They have noted that during the postreinforcement pause following response-contingent food reinforcement, pigeons are unlikely to engage in pecking behavior that initiates a fixed-interval period (Shull, 1970), terminates a reinforcement schedule (Brown \& Flory, 1972), or increases reinforcement rate. Although the results of this experiment cannot account for the post-reinforcement inhibition of keypecking, they do rule out the hypothesis (Innis \& Honig, 1979) that, following food reinforcement, pecks that topographically resemble feeding behavior are inhibited. This is not the case, since vigorous feeding-like pecks readily occur immediately following food reinforcement when those pecks are directed toward the head of a conspecific target located away from the reinforcer dispenser.

\section{GENERAL DISCUSSION}

The results of these experiments indicate that intermittent presentations of water and food are similarly effective in engendering schedule-induced attack in pigeons. When exposed to a fixed-time $90-\mathrm{sec}$ reinforcement schedule with a conspecific target available, the percentages of water- and food-reinforced birds exhibiting sustained levels of attack were the same. Furthermore, the rates of attack were comparable and the topography and duration of targetdirected pecks under both reinforcement conditions were similar to the pigeon's feeding pecks. The results thus indicate that schedule-induced attack in pigeons is a general effect of intermittent positive reinforcement.

Although both reinforcers were effective in inducing attack, the temporal organization of behavior within the interreinforcement interval differed both prior to and after target introduction. With a target unavailable, pigeons exposed to intermittent water presentation spent more total session time in the vicinity of the dispenser than birds on a comparable food schedule. Both food- and water-reinforced birds tended to walk away from the dispenser following the withdrawal of the reinforcer, although this movement typically occurred later in the interval for water-reinforced than for food-reinforced birds. Unlike food-reinforced birds, water-reinforced subjects displayed drinking-like behaviors in and around the vicinity of the water dispenser for some time following reinforcement termination (Reberg et al., 1978). Such a tendency to perseverate in an area associated with water has been reported for rats in other contexts (Logan \& Spanier, 1970; Petrinovich \& Bolles, 1954) and may be, in part, a behavioral manifestation of the tendency in nature for water to be localized in one area rather than dispersed like food.

In general, the different temporal, spatial, and topographic organizations of behavior for food- and 
water-reinforced birds prior to target introduction were reflected in the subsequent temporal organizations of attack against the conspecific target. Unlike food-reinforced subjects that exhibited maximum rates of schedule-induced attack within $15 \mathrm{sec}$ of reinforcement termination, maximum attack rates for water-reinforced birds typically occurred $15 \mathrm{sec}$ or more after termination of the reinforcer. This delayed onset of attack following water presentation is consistent with King's (1974) observation that adjunctive wheel-running in rats tends to occur later in the interval following water than following food presentation, and also with his suggestion that another behavior (such as postreinforcement rooting) may displace an adjunctive behavior away from the immediate postreinforcement period.

The delayed onset of attack following water reinforcement is also consistent with increasing evidence that adjunctive attack is not temporally linked to reinforcement termination in a rigid manner. In pigeons, schedule-induced attack does not always initially occur in the immediate postreinforcement period but can develop into that pattern over several sessions (Yoburn \& Cohen, 1979). Similarly, attack can be displaced away from the immediate postreinforcement period by imposing a time-out immediately following reinforcement (DeWeese, 1977) or by making a target available only later in the interreinforcement interval (Muller \& Cheney, Note 1).

The specific relationship between post-water reinforcement, rooting-like activities, and adjunctive attack in this experiment remains uncertain and deserves further study. One possibility is that hopperdirected activities reflect a postreinforcement inhibition of an aroused state (Killeen, 1979) that engenders attack. In that case, postreinforcement rooting in the water magazine and the delayed onset of attack following water reinforcement would reflect a postreinforcement inhibitory process with a relatively long decay time. This interpretation, in conjunction with Killeen, Hanson, and Osborne's (1978) experiments with food reinforcement, suggests that the decay time of the inhibitory process is longer for water than for food reinforcement, leading, in the latter case, to a longer latency to attack. Additional work with water and food reinforcement must examine this hypothesis as well as alternative interpretations (Solomon, 1980), including the possibility that postreinforcement rooting is itself an adjunctive behavior that successfully competes with adjunctive attack.

\section{REFERENCE NOTE}

1. Muller, P. G., \& Cheney, C. D. Varying the temporal location of the opportunity to attack within the interfood interval. Paper presented at the meeting of the Psychonomic Society, Denver, November 1975 .

\section{REFERENCES}

Azrin, N. H., Hutchinson, R. R., \& Hake, D. F. Extinctioninduced aggression. Journal of the Experimental Analysis of Behavior, 1966, 9, 191-204.

Baum, W. M., \& Rachlin, H. C. Choice as time allocation. Journal of the Experimental Analysis of Behavior, 1969, 12, 861-874.

Boshka, S. C., Weisman, H. M., \& Thor, D. H. A technique for inducing aggression in rats using morphine withdrawal. Psychological Record, 1966, 16, 541-543.

Brown, T. G., \& Flory, R. K. Schedule-induced escape from fixed-interval reinforcement. Journal of the Experimental Analysis of Behavior, 1972, 17, 395-403.

DEWEESE, J. Schedule-induced biting under fixed-interval schedules of food or electric-shock presentation. Journal of the Experimental Analysis of Behavior, 1977, 27, 419-432.

FALK, J. L. The nature and determinates of adjunctive behavior. Physiology \& Behavior, 1971, 6, 577-588.

FALK, J. L. The origin and functions of adjunctive behavior. Animal Learning \& Behavior, 1977, 5, 325-335.

Frederiksen, L. W., \& Petersen, G. L. Schedule-induced aggression in humans and animals: A comparative parametric review. Aggressive Behavior, 1977, 3, 57-76.

Gallup, G. Aggression in rats as a function of frustrative nonreward in a straight alley. Psychonomic Science, 1965, 3, 99-100.

Gentry, W. D., \& Schaeffer, R. W. The effect of FR response requirement on the aggressive behavior in rats. Psychonomic Science, 1969, 14, 236-238.

Huston, J. P., \& DeSisto, M. J. Interspecies aggression during fixed-ratio hypothalamic self-stimulation in rats. Physiology \& Behavior, 1971, 7, 353-357.

Hutchinson, R. R., \& EmLey, G. S. Effects of nicotine on avoidance, conditioned suppression and aggression response measures in animals and man. In W. L. Dunn (Ed.), Smoking behavior: Motives and incentives. Washington, D.C: Winston, 1973

Hutchinson, R. R., Pierce, G. E., Emley, G. S., Proni, T. J., \& SAUER, R. A. The laboratory measurement of human anger. Neuroscience and Biobehavioral Reviews, 1977, 1, 241-259.

Hutchinson, R. R., \& Renfrew, J. W. Functional parallels between the neural and environmental antecedents of aggression. Neuroscience and Biobehavioral Reviews, 1978, 2, 33-58.

Innis, N. K., \& Honig, W. K. Stimulus control of behavior during the postreinforcement pause of FI schedules. Animal Learning \& Behavior, 1979, 7, 203-210.

Jenkins, H. M., \& Moore, B. R. The form of the autoshaped response with food or water reinforcers. Journal of the Experimental Analysis of Behavior, 1973, 20, 163-181.

Killeen, P. R. Arousal: Its genesis, modulation, and extinction. In M. D. Zeiler \& P. D. Harzem (Eds.), Advances in analysis of behavior (Vol. 1) Reinforcement and the organization of behavior. Chichester, England: Wiley, 1979.

Killeen, P. R., Hanson, S. J., \& Osbohne, S. R. Arousal: Its genesis and manifestation as response rate. Psychological Review, $1978,85,571-581$.

KING, G. D. Wheel running in the rat induced by a fixed-time presentation of water. Animal Learning \& Behavior, 1974, 2, 325-328.

Logan, F. A., \& Spanier, D. Relative effect of delay of food and water reward. Journal of Comparative and Physiological Psychology, 1970, 72, 102-104.

Looney, T. A., \& Cohen, P. S. Pictorial target control of scheduleinduced attack in White Carneaux pigeons. Journal of the Experimental Analysis of Behavior, 1974, 21, 571-584.

MCFarland, D. J. Mechanisms of behavioral disinhibition. Animal Behaviour, 1969, 17, 238-242.

Petrinovich, L., \& Bolles, R. Deprivation states and behavioral attributes. Journal of Comparative and Physiological Psychology, 1954, 47, 450-453. 
Reberg, D., Innis, N. K., Mann, B., \& Eizenga, C. 'Superstitious' behavior resulting from periodic response-independent presentations of food or water. Animal Behaviour, 1978, 26, 507.519.

RilLiNG, M. Stimulus control and inhibitory processes. In W. K. Honig \& J. E. R. Staddon (Eds.), Handbook of operant behavior. Englewood Cliffs, N.J: Prentice-Hall, 1977.

Rowell, C. H. F. Displacement grooming in the chaffinch. Animal Behaviour, 1961, 9, 38-63.

SHULL, R. L. A response-initiated fixed-intereval schedule of reinforcement. Journal of the Experimental Analysis of Behavior, $1970,13,13-15$.

Solomon, R. L. Recent experiments testing an opponent-process theory of acquired motivation. Acta Neurobiologiae Experimentalis, 1980, 40, 271-289.

Thompson, T., \& Bloom, W. Aggressive behavior and extinctioninduced response rate increase. Psychonomic Science, 1966, 5, 335-336.

Wolin, B. R. Difference in manner of pecking a key between pigeons reinforced with food and water. In A. C. Catania (Ed.), Contemporary research in operant behavior. Glenview, Ill: Scott, Foresman, 1968.

YoвURN, B. C. Induction of attack in White King pigeons by intermittent reinforcement. Unpublished $\mathrm{PhD}$ thesis, Northeastern University, 1979.

Yoburn, B. C., \& Cohen, P. S. Assessment of attack and drinking in White King pigeons on response-independent food schedules. Journal of the Experimental Analysis of Behavior, 1979, 31, 91-101.

Yoburn, B. C., Cohen, P. S., \& Campagnoni, F. R. The role of intermittent food in the induction of attack in pigeons. Journal of the Experimental Analysis of Behavior, 1981, 35, 101-117.

ZEIGLER, H. P. Feeding behavior of the pigeon. In J. Rosenblatt, R. A. Hinde, E. Shaw, \& C. Beer (Eds.), Advances in the study of behavior (Vol. 7). New York: Academic Press, 1976.

(Manuscript received November 5, 1980; revision accepted for publication March 9, 1981.) 